serere cases were treated, the diet was, almost without exception, one of pure milk. This alone was given until the temperature had remained below $99^{\circ} \mathrm{F}$. for a period of 10 days. As we only admitted cases of especial severity our mortality exceeded the total rate considerably, 12.5 per cent. Many of the deaths were from pneumonia soon after admission; only one relapse occurred, and intestinal conplications were remarkably few in view of the gravity of the cases.

I am, Sirs, yours faithfully,

Fred. T. Travers. B.S. Lond., F.R.C.S. Edin., Surgeon to West Kent General Hospital, Maidstone.

\section{ACUTE DILATATION OF THE STOMACH.}

To the Editors of THE LANGET.

SIRS, - The views communicated by me to THE LANCET of Nov. 2nd, p. 1228, so far as they relate to duodenal pressure-obstruction, have been paid the compliment of a notice by Dr. Theodore Fisher and that of adoption by Dr. C. R. Box and $\mathrm{Mr}$. O. S. Wallace. Indirectly they derive some importance from the circumstance that in this country, so far as I am informed, no recognition had previously been awarded to the three fundamental points in connexion with this affection viz., (1) the evidence that obstruction is the mechanism of the dilatation; (2) the localisation of the obstruction in the third part of the duodenum; and (3) the special indications for its treatment. I wish to be corrected if it should be a false impression that the articles embodying the recent teaching on this subject and the discussion before the Royal Medical and Chirurgical Society had left us without any definite etio$\log y$, without any mention of duodenal occlusion, ${ }^{1}$ and without any adequate suggestion for its relief, but still committed to a mysterious theory of active paralytic expansion for which strychnine would be a suitable treatment. From the papers of Dr. Box and Mr. Wallace in the Transactions of the Clinical Society of London for 1898 and in THE LANCET of Nov. 9th, 1901, p. 1259, it must be concluded that they have now largely modified their original view in favour of the principle of duodenal occlusion and of the therapeutical consequences which it involves. I entirely agree with their remark that a correct diagnosis has been found by many to be a matter of difficulty, though it ought not to be difficult. Moderate cilatations would still more readily be overlooked; and, indeed, this very frequently happens. In this connexion it is necessary to mention that very few, if any, of the published cases of so-called "acute dilatation" are provided with satisfactory evidence that gastric dilatation did not obtain in them prior to the acute symptoms for this opens up important considerations to which I shall presently allude. Although the results of post-mortem experiments can hardly be applied without reservations to the elucidation of the behaviour of morbid viscera, satisfactory evidence has been obtained by Dr. Box and $\mathrm{Mr}$. Wallace that a stomach charged with a sufficient weight of fluid will avail to compress the duodenum against the spine; and this furnishes a reply to the doubt expressed by Dr. Fisher, by demonstrating one of the modes in which a duodenal occlusion which might have been slight at first may be made absolute by a growing distension of the stomach. This instructive experiment may also explain one of the modes of origin of the occlusion. The water-pressure sufficed in itself to keep up the obstruction even after the overstretched tissues overlying the trans verse portion of the duodenum had been divided. By their division the outflow on raising the fundus from the spine would be facilitated, but it is not proved that so long as they remained undivided they did not avail to check it at least in part.

From a practical standpoint the most important questions are the antecedent condition and the determining cause as possible guides to prevention and to timely treatment. It is probable, and it may eventually be proved, that gastric dilatation and gastroptosis are antecedents in a majority of the cases, whilst exhaustion, combined with malnutrition or marasmus, is a specially predisposing cause. The chief determining cause is atony of the stomach (particularly if associated with intestinal collapse) in combination

I I find that the recent work of Mr. Mayo Robson and Mr. B. G. A $\mathrm{M} Y \mathrm{y}$ han contains a short reference to the subject, in connexion with P. Millers paper in the Deutsche Zeitschrift fur Chirurgie, Augus ${ }^{+}$ 1900. with continued dorsal decubitus. This causation belongs to cases which are found after death to be free from coarse structural lesions; but in other instances various local abnormalities may take a large share in the result. In cases of pure debility from abdominal marasmus, surgical shock, or toxæmia, the dorsal decubitus places the enfeebled. gastric and duodenal peristalsis at a disadvantage ; but in the stage of exhaustion when enteroptosis or a previous gastric dilatation has caused the pyloric portion to subside into the right vertebral groove it becomes a danger. This should be borne in mind in predisposed ca:es, particular]y after severe operations ; for in the early stage the progressive duodenal compression might be prevented by suitable posture, or by other means if the patient be unable to be moved. Concerning operative measures, should they become necessary, I cannot venture to speak without diffidence, but I cling to the impression that gastro-jejunostomy may not be the only, and may not in all cases be the most desirable, procedure, and that something might perhaps be acbieved by suitable. manipulation of the viscera in cases where the postural method can be applied after the operation.

In conclusion, these fragmentary suggestions cannot pretend to do full justice to the intricate subject, or to the writer's views. There are various forms of "duodenal pressure-obstruction," a separate discussion of which is beyond the compass of this communication. But the essential has been done if sufticient attention has been called to its existence, as a first step towards its successful treatment. I am, Sirs, yours faithfully,

Curzon-street, W., Nor. 11th, $1901 . \quad$ WIILIAM EWART.

\section{THE PREVENTION OF ASPHYXIA WHEN THE BIRTH OF THE AFTER-COMING, HEAD IS DELAYED: A HISTO- RICAL NOTE. \\ To the Editors of THE LANCET.}

SiRs,-Allow me to say a few words in reply to Dr. G. F. Blacker's "Historical Note" in THE LANCET of Oct. 19th, p. 1033. Dr. Blacker says: "The passage of a catheter or special tube into the child's mouth when the head is lying high up in the pelvic cavity is only likely to lead to a waste of valuable time, while if the head is sufficiently low down in the pelvis to admit of air reaching the mouth if the perineum be retracted its immediate extraction should be a matter of little difficulty," and later he quotes Dr. Barnes : "The real problem is to get the head out of the pelvis," to which he adds, "And to this advice one may safely add the qualification, as rapidly as possible."

Firstly, I would say that the passage of a catheter into the child's mouth when the head is lying high up in the pelvic cavity would be utterly unnecessary, inasmuch as the circulation of the cord would not be in any way obstructed. When, however, the bead is sufficiently low so that pressure on the cord results it is, I believe, always possible to find the mouth with a catheter guided by the finger. The waste of valuable time exists only in Dr. Blacker's imagination; the veriest bungler would have the catheter in the child's mouth in three seconds, and every midwifery bag contains a catheter. Dr. Blacker then goes on to say that, " if the head is sufficiently low down in the pelvis to admit of air reaching the mouth if the perineum be retracted its immediate extraction should be a matter of little difficulty." Now, I should like to ask a question: How does Dr. Blacker account for the high mortality of breech cases if this assertion be true? Anyone will tell him that it is possible for the mouth to be well within reach of the finger and yet for the occipito-frontal diameter of the child's head to be fixed in one of the oblique diameters of the pelvis. Indeed, this is where the hitch usually occurs, and it is then that the pressure on the cord takes place, and it is then that Dr. Blacker recommends that somewhat difficult operation of applying the forceps, an operation which necessitates a delay of at least three or four minutes. Again, traction on the jaw is recommended, a most iniquitous proceeding to my mind. Think of it-the act of pulling forcibly upon the jaw of a tender infant! To do any good at all it must be forcible, and if the children on whom it has been practised were followed up who knows but what it would be found that they developed into those unfortunate people who are always dislocating their jaws at awkward moments. Balance the "valuable time" lost in inserting the catheter against four minutes required for apply.ng the 
forceps ; also, the forceps can still be applied, if necessary, with the catheter in situ. Traction on the jaw I put in the category of "meddlesome midwifery"; in fact, the less. traction we indulge in the better, for traction of itself has great and serious dangers. Finally, I submit that the "real problem" is not "to get the head out of the pelvis as quickly as possible" ; it is absolutely and seriously different ; it is to bring a living child into the world with the least possible amount of damage to it or the mother. I admit that I have only had one cathetered case on which to argue (my "one ounce of practice"), but I have not the slightest doubt that if a catheter was passed as routine treatment when the hitch occurred, followed by a masterly inactive wait, finally forceps if necessary, we should have an upheaval of statistics of mortality in breech presentations; if, on the other hand, we follow Dr. Blacker's precepts the mortality of 1 in 11 (Dubois) or 1 in $3 \frac{1}{5}$ (Churchill) will stand for aye.

Queen's-road, Richmond. I am, Sirs, yours faithfully,

GEORGE W. ORD.

\section{A SIMPLE APPARATUS FOR ETHER NARCOSIS.}

To the Editors of THE LANCET.

SIRS,-In The LANCET of Nov. 9th, p. 1297, I observe a letter by Dr. Leonard Williams describing an ether inhaler which had been shown to him some months previously by Dr. Longard of Aix-la-Chapelle. As the inhaler referred to by Dr. Williams is practically identical in design and appearance with that devised by me 17 years ago and described in THE LANCET of July 5th, 1884, p. 19, it will be interesting to learn the source from which the inhale recommended by Dr. Longard has originated.

I am, Sirs, yours faithfully,

P. Blaikie Smith, M.D. Aberd.

San Remo, Italy, Nov, 16th, 1901

\section{THE FREEZING-POINT OF THE 'BLOOD AND SECRETIONS AS AN AID TO PROGNOSIS. \\ To the Editors of THE LANCET.}

SiRs,-I read Professor Ogston's article on cryoscopy in THE LANCET of Nor 9th, p. 1253, with great interest but I finished it unconvinced of the unique value which he claims for the new procedure probably through my want of understanding, and $I$ am sure he will accept my criticisms as made in the spirit of inquiry. In the first place the value of the observations recorded is much diminished by our ignorance of the cause of the variation in the freezingpoint of the blood; in no instance is this more evident than in the cases where it is above normal. Professor Ogston in regard to this writes of an "unusual purity" of the blood. If his milkman were to supply him with milk deficient of 10 per cent. of its cream and of too light a specific gravity would he regard it as unusually pure? And how are we to rely on cryoscopy as an indication of renal sufficiency or insufficiency if, as is stated, it is also an index of hepatism ? However, I chiefly wish to consider the practical bearing of this test, and this is best done by taking seriatim the cases advanced as proof of its value, assuming that the essential facts for such proof are quoted. I fail to see, almost without exception, that anything has been proved that could not have been proved with other more definite and better understood tests.

In Case 1, assuming that disease indicating casts were absent and that the total output of urea was satisfactory, a trace of albumin would hardly be considered a contra-indication to study. In Case 2 we are not told the specific gravity of the urine or the daily outpnt of urea or the cause of death, so that no estimate of the value of cryoscopy is here possible. In Case 3 the test is superfluous. In Case 4 might not the cryoscopy taken at different times have shown as variable a condition of the blood as the specific gravity did of the urine? -there was here no indication of renal insufficiency. In Case 5 there appears to have been no contra-indication to work, so that the test was superfluous. In Case 6 (the reading given being 0.556 , I assume that a different scale has been used from that described) why is $\tau^{4} 0^{\circ}$ above normal slightly unfavourable when Cases 1 and $4,1^{3}{ }^{\circ}$ and $\frac{2}{100^{\circ}}$ above normal, are favourable indications? In Case 7 we are not told the blood-count or whether the specific gravity of the urine is for the 24 hours. And how does the cryoscopy prove "that the kidneys, though diseased, were not the cause of the deterioration." In Case 8 we want an estimate of the urea, but with an albuminous urine having a specific gravity of 1006 the patient would surely in any event have been considered an unfit subject for operation. In Case 9, if, as it appears, the blood was tested after the operation, may not its abnormal condition have been brought about by the "lessened kidney elimination that follows operations ...... performed under an anæsthetic"? In Case 10, although the urea eliminated was low, the patient "wa greatly wasted," so that without her bodyweight being stated the estimate loses its value as an indication of renal insufficiency, and why in this case is $\frac{1}{10} \sigma^{\circ}$ below normal "only" 10 ${ }^{\circ}$ when in Case 2 Iั $^{\circ}$ " was sufficient to indicate a probably fatal result after operation? In Case 11 criticism is impossible as facts as to tube casts and elimination of urea are not given. In Case 12 does cryoscopy$-0.59^{\circ}$-indicate anything more than albuminous urine with specific gravity 1002 does?

Professor Ogston probably would not suggest that cryoscopy should take the place of the usual examination of the urine or blood, but that it should serve as an adjunct to these to increase the value of the deductions drawn from them; but as yet it seems to me the positions must be reversed, and careful chemical and microscopical examinations of the urine and blood be made to enable us to estimate the value and meaning of the variations in the freezing-point of the blood Doubtless further observations will clear up many points, such as diurnal variation of the freezing-point and the meaning of readings above normal, and your readers will, I am sure, look forward with much interest to further developments in this promised aid to clinical diagnosis.

I am, Sirs, yours faithfully,

Bradford-on-Avon, Nov. 11th, 1901. CHAS. E. S. FuEMming

\section{FOREIGN BODY IN THE RECTUM.}

\section{To the Editors of THE LANCE'T.}

SIRS, - I have been asked, whether the retention of urine in my case was due to reflex action through the presence of the foreign body in the rectum. Certainly not. In the first place the old man possessed a blunted sensibility that would allow of the infliction of an unusual amount of pain without producing any reaction ; furthermore, the bulk of the bottle, its position within the rectum and the pressure caused by the firmness with which it lodged on the coccyx, were sufticient reasons for retention of urine. I consider that the neck of the bottle impinging on the floor of the bladder paralysed the action of the vesical extrusive muscles and that the bottle was forced into this tight position by the frantic efforts made to recover it after it had escaped into the rectum.

Stockport, Nov. 12th, 1901.

I am, Sirs, yours faithfully,

J. GOOD.

\section{A QUESTION OF SPELLING.}

To the Editors of THE LANCET.

SIRS,-I noticed that as in Sir William Gowers's case you substituted "faradaic" for "faradic" in a recent lecture of mine, and there is no doubt that you were correct, or more correct than I was, although it is certain that "faradic" will become the word par excellence in future on the ground of brevity and euphony, just as "telegram," in spite of all rules to the contrary, has superseded the less elegant "telegraph." After all, it is use and convenience that must guide us in such cases ; as Horace has remarked,

Quem penes arbitrium est et jus et norma loquendi."

l am, Sirs, yours faithfully,

C. BeLL TAYLOR, M.D. Edin.

(Arbitrium est et jus et norma loquendi.)

** It is correct to say "to telegraph" and "a telegram." "Telegraph" is the infinitive form of a Greek verb and "telegram" is the neuter noun form, derived from the past participle of that verb. "Telegraph" is used sometimes as a noun interchangeable with "telegram "-presumably on the analogy of the use of the word "photograph," but although 